\title{
TECHNOLOGICAL POTENTIALS IN HOME CONSTRUCTION
}

\author{
ROBERT L. DAvison*
}

The most serious handicap to progress in technical developments in the planning and construction of dwellings is the widespread feeling that housing, like the fine arts, is not subject to a rational approach or rational solution.

The analogy of the automobile and house has become the stock illustration for most articles on new materials and methods. "Prefab enthusiasts" maintain that houses could be produced in factories with belt-line production methods comparable to those used in the automobile industry. On the other hand, there are building contractors and other "practical men" in the building field stating that houses cannot be produced like Fords. People using the automobile analogy, and most readers, overlook the fact that the automobile is not a mass produced horse and buggy. The motor is not an evolutionary development of the horse. The horse cannot be assembled like a Ford motor, and neither can the traditional house be so assembled. The true understanding of the automobile analogy implies the development of a completely different kind of shelter than that which we think of at the present time as a home. In the same sense that the automobile is an improved form of transport rather than an improved horse and buggy, the dwelling of the future will be an improved form of shelter and equipment for family living rather than an improved traditional house. We had to change our thinking from animal husbandry to mechanics to get much better transportation and now we might do well to change our thinking from materials and methods, formerly the only possible ones, to those new materials and methods which can now be made available through the enormous increase in scientific knowledge gained in recent years.

\section{Technical Approach}

An extreme example of what a scientific approach to the problem of developing an ideal environment for living would be can be illustrated by reference to the work of Professor J. D. Bernal, a crystallographer who is now head of housing research for the English Government. He asked himself: "What molecular structure would make an ideal exterior wall?" Among the qualities set up as desirable was a

* Director of Robert L. Davison Associates (housing research) 1944 to date; Director of Research, the John B. Pierce Foundation, 1931-r934; Director of Rescarch, the Architectural Record, 1929-1930; con. sultant to: Smaller War Plants Corporation (1944), War Production Board (1942), Department of Commerce (1940), League of Nations (1938), Resettlement Administration (1935), Subsistance Homesteads Administration (1933). Served on various committecs of: American Public Health Association, American Standards Association, National Housing Committce, American Society of Mechanical Engincers. Author of numerous articles in architectural, technical, economic and general periodicals. 
crystalline structure which would not have cleavage planes between groups of atoms, would be transparent to high temperature radiation from the sun, and opaque to heat from comparatively low temperature sources, such as might occur within the building. He had many other qualities which he considered desirable, such as wide spacing of atoms of molecules to obtain lightness, elasticity, etc. He finally found a crystalline form in the joint of bamboo-a vegetable silicate-which closely approximated his theoretical ideal. Let me quote from him as follows:

"The aerogels which are found in certain plant products, notably in the silicified pith of bamboo, can now be made in the laboratory as hard solids several times lighter than cork and practically perfect insulators against heat. They also have the incidental advantage of being completely fire-proof. If such material could be produced on a large scale, walls and partitions could be made from slabs weighing about I lb. per square foot."

Needless to say, as Director of Housing Research for the English Government, he is not waiting for himself or anyone else to find the correct molecular structure of an ideal wall, but this type of thinking and this method of approach are necessary before any important results will be obtained in this field or we can even recognize "technological potentials in home construction."

\section{BuILDING Codes}

The second important handicap is the "bugaboo" of building codes. It is beginning to be recognized that no important improvements can ${ }^{-b e}$ made under present building codes. Codes should be put on a scientific basis. In recent years a great deal has been written and said about the substitution of "performance requirements" for detailed specification as now used in most building codes. While this is a desirable step, there is a real hazard in the setting up of performance requirements unless these performance requirements are realistically related to actual functional needs. I should like to differentiate between performance requirements and functional performance requirements by giving an example. In Report BMS92 "Fire-Resistance Classifications of Building Constructions" of the National Bureau of Standards, issued October 7, I942, the following definition is given:

"Fireproof Construction

(Ist part.) That type of construction in which the structural elements are of incombustible materials with fire resistance ratings sufficient to withstand the fire severity resulting from complete combustion of the contents and finish involved in the intended occupancy

(2nd part.) but not less than the rating specified in table $1 . .$. . (The italics are mine.)

The first part of this definition is the type of functional performance requirement that should, in principle, be applied to all types of housing regulation. This first part of the definition was put in at the insistance of the most progressive members of the committee drafting this report-the latter part by the conservatives. In offthe-record discussions the conservatives agree that the latter part of the definition sets up test conditions much more severe than those called for by the first, or func- 
tional performance requirements part of the definition, and it is questionable whether the second part does not negate the first.

Many of the most promising materials and methods would pass the functional performance requirements but not the arbitrary requirements as "specified in Table r." For example, Foamglas (which is the only rigid insulating material which is of itself completely vaporproof) would not in economical thicknesses meet "ratings specified in Table $\mathbf{r}$," and therefore would be eliminated from consideration as a wall material for multi-story housing. Foamglas is not necessarily the best material or the only material that can be used for curtain walls, but it should be judged on its merits. Progress in this field is going to be very seriously handicapped if those in control of research policy, or research technicians, limit their research to methods acceptable under present codes or officially recommended performance requirements when these performance requirements are not realistic in a technical sense.

It is not only as regards fire tests that our codes are needlessly restrictive, but design loads are often needlessly high. Excessive factors of safety (which is often by the more progressive engineers called "factor of ignorance") cause overdesign and add cost.

These restrictive code elements are not limited to materials and methods utilized for the walls, floors, frame of the building, etc., but are perhaps even more restrictive in the field of mechanical appliances and equipment. Not only do they make equipment cost more than it should and greatly increase the labor required to install it, but these code requirements prevent progress in the development of more efficient plans. With a scientifically logical and rational building code, it might well be economically sound to provide a lavatory in each bedroom in addition to central bath and water closet. Our grandfathers had a wash basin in each bedroom and we might also have a low-cost concealed type if we had a rational plumbing code.

The minimal area of rooms for various uses, ceiling heights, window areas, etc., are sometimes covered in building codes and sometimes in special housing or health codes. Here we have specification approach to the problem of providing healthy surroundings. Due to lack of detailed knowledge of what constitutes a healthy environment, minimum space standards have been arbitrarily established. These are supposedly based on cubic feet required to maintain bodily health, but are actually based on area assumed to be required for furniture and circulation or psychological data. It would be most undesirable if technicians engaged in housing research were to permit these minimal space requirements to limit their approach to the housing problem. For example, go square feet has often been set as a minimum floor area for a bedroom. It is quite possible that a room of 70 square feet having a disappearing bed would be preferable if judged on a basis of functional performance. It might even be more desirable to have two bedrooms each of 45 square feet floor area than a $90 \mathrm{sq}$. ft. room occupied by two people, if proper light, ventilation, equipment, disappearing bed, etc., are provided.

If the technological approach to the housing problem and the functional per- 
formance requirement approach to the building code is accepted, we may expect in the relatively near future radical new materials, new construction methods, and improved equipment and planning.

\section{New Insulating Materials for Curtain Walls}

The material nearest in principle to Bernal's "Molecular Wall" is "Santocel," a material now in production by Monsanto Chemical Company. Sontocel is a silica aerogel, a very light porous form of silica, weighing 5 pounds per cubic foot. The air spaces in Santocel are so small that they are said to not only prevent convection currents, but effectively interfere with inolecular movement. Monsanto claims a heat loss for one inch thickness of only 0.15 Btu per hour per square foot per Degree Fahrenheit, which is ro percent better than theoretically "still air."

At the present time this material is too expensive for use as a curtain wall for enclosing a dwelling space. Its commercial use will probably, for the first few years, be confined to insulating refrigerators where its greater resistance to heat transfer than previously used materials will permit the use of reduced thicknesses of insulation, thus increasing the net usable cubic content of the refrigerator without increasing over-all size. This same principle will be of considerable value when applied to housing. For example, with a material of this character a I-inch thick wall would have an insulating value more than twice that of a 12-inch brick wall. While this decrease in heat loss from the wall of a building might save only two cents or three cents per square foot of wall per year, the increase in comfort together with the rapidity with which the building could be heated up in the morning would be of considerable value.

From the standpoint of economics the most important factor would be the elimination of space now wasted in the exterior wall of most multi-story buildings. In an office building this would lead to an increase in net rental return from the building of $\$ 2.00$ to $\$ 3.00$ per lineal foot of exterior wall per floor per year-a nice increase in net profit before taxes. In an apartment building this increased profit would be less, but still good.

Another of the "technological potentials" which, while having perhaps less scientific "potential" than the silica aerogel just referred to, is at the present time being used in the building industry, is Foamglas. This is a foamed glass weighing approximately II pounds per cubic foot. At present this material is largely used as insulation in cold storage plants or roof insulation in buildings where it is important to guard against any possibility of condensation within the insulation material. In the future it may well be used as the core material for metal-faced curtain wall panels.

One of the principal reasons for using Foamglas is that it is the only rigid type insulating material that of itself, without an added vapor barrier, is proof against internal condensation of water vapor: Also, being glass, it is probable that it would last indefinitely if not subjected to excessive vibration or shock. While in all prob- 
ability it would withstand a functional performance requirement fire test-i.e., complete combustion of the contents of an apartment without failure-it would probably not qualify in economic thicknesses as a core material for metal-faced exterior wall panels under most existing building codes, or even under proposed model codes, as the test temperatures exceed the melting point of glass. Since the standard test quickly melts window glass, it is customary in testing walls having window openings, to brick up the window openings so as to permit a realistic (?) test of the wall only. Under these standard test conditions Foamglas, even encased in steel, will melt before the bricked up window openings in the test panel. Yet it would withstand a functional performance test.

Several other materials besides Foamglas could be used for the core of a metalfaced spandrel wall. One, calcium hydrosilicate-previously known as Microporite and now called Kaylo-would, in 3-inch thickness, stand a severe fire test. This material is more rugged than the Foamglas and has very high fire resisting qualities which would doubtless withstand a two- and possibly a four-hour test. With the use of a material such as this or any material not absolutely vaporproof like Foamglas, it is necessary to hermetically seal the panel on the inside or provide ventilation of the exterior wall surface to remove any moisture that might get into the insulation.

There are various foam plastics which are of very great interest and may some day be used extensively as core material for metal wall units. The great advantages from the use of some of these plastics is their elasticity and light weight, which means high insulation value and easy transportation and installation. The disadvantages are lack of fire resistance-which may be partly compensated for by the metal surface-and high price per pound. Prices will decrease as these materials reach a point of oversupply. When the light weight of these foam materials (4 to $6 \mathrm{lbs}$..per cubic foot) is considered and the fact that less than one-fourth of a cubic foot is needed for a square foot of wall, a cost per pound of twenty cents to thirty cents is not so prohibitive. A price of ten cents might permit use of these panels in single-family residences.

Due to limited availability and the high prices of Foamglas, Kaylo, and foam plastics, probably the early types of metal-encased insulating material for curtain walls will have cores of vermiculite in board form, lightweight gypsum, or lightweight foam fiber concrete.

\section{Surface Material}

The selection of metal surfaces to enclose these various insulating materials has many pros and cons. Aluminum, due to its non-corrosive feature and lightness, has many qualities that recommend its use, particularly for dwelling construction under four stories in height. If aluminum were used with a combustible foam plastic, it might be safe for three- or four-story apartments, provided there was no 
serious conflagration hazard from adjacent property. In higher apartments where egress in case of fire would be slower, it is desirable to have a higher degree of fire resistance of core, or surface, or both.

The best protection against loss of life in case of fire is probably the provision of enclosed fire stairs with exterior entrances and exterior venting. If you think back you will remember that loss of life in recent hotel or apartment fires has been generally due to smoke or burning of the interior of the building. The fact that the exterior wall had a four-hour fire rating was of no apparent help in preventing loss of life:

Once window glass is broken (say five minutes) the wall itself offers little protection to life against exterior fire hazard. Fireproof interior doors and partitions are much more important, as most fires originate indoors.

Calcium hydrosilicate, vermiculite or other lightweight concretes would probably give a reasonable degree of fire protection even though encased in aluminum, which in itself would not withstand prolonged exposute to fire. Here again we are not too sure of what a sensible functional perforriance standard would be until experimental structures have been built with some of these new materials and then tested. Copper would withstand fire tests better than aluminum and has other qualities to recommend it for metal enclosure of insulated wall panels. The most serious handicap to the use of copper is the difficulty in obtaining a pleasing finish. We have all seen copper with a beautiful patina finish, but so far it has apparently been impossible to obtain a lasting artificial 'patina finish. We may find some method of preserving the natural copper or bronze finish, or some transparent plastic film may be developed which will protect an artificial patina. If such a finish can be found the question naturally arises as to the need of using copper and one wonders why not apply such finish direct to steel at a considerable saving in first cost. There seems to be considerable doubt that such a plastic finish is available at the present time, but there is hope that a resin impregnated sheet fiber may be developed which can be laminated to metal, giving a surface treatment in color, which we may reasonably hope will have a life of thirty or forty years. If accelerated tests indicate that this is probable, such finishes might be applied to steel with the hope that they will last the life of the building. Should they show failure earlier than tests have led one to expect, it would not be too difficult to extend the life of the surface by giving a resin spray coat.

One of the interesting possibilities for surface metal treatment is the use of an I8 chrome 8 nickel steel, generally called stainless steel, such as was used for the exterior trim of the Empire State and Chrysler Buildings. For residential construction this bright finish might be objectionable, and a modified form used. Ten or twelve percent chrome steel pre-oxidized to a dark brown or black, might prove to be one of the practical metals for apartment houses of the future. 


\section{Floors, Roof and Partitions}

Generally (and this discussion is no exception) there is over-emphasis on the problem of exterior walls when discussing new construction methods. One reason for this is that exterior walls look larger in the budget than any other single item except combined mechanical equipment. Another reason the exterior wall receives more attention is that it is more difficult to meet all the requirements for an exterior wall than it is for the other elements in the house. For example, many codes require exterior walls in buildings over four stories to be of non-combustible material and to stand a four-hour test, while floors in buildings to six stories in height may be of wood and plaster construction and pass only a one-hour fire test. Walls have problems of waterproofness, internal condensation, weatherability, and exterior appearance, while interior partitions do not have to meet these problems and surfaces can be painted or papered, eliminating the basic problems of appearance. It should be obvious that the general principles of a lightweight core with a metal stress skin can also be used for interior floors and partitions. For floors the emphasis would shift from heat insulating to sound insulation with the determining factor as regards strength being the ability to withstand everyday load conditionsnotably concentrated live load or vibration-and to withstand actual possible maxi-. mum concentrated load conditions without failure of the structure. Generally speaking, from a functional performance standard, the maximum distributed functional load has been assumed in the past to be that which may occur at a funeral. This generally accepted principle existed before the time of the "jitter-bug," and further study might indicate that a high school party would be the maximum load for which a floor should be designed. The fact remains that no one knows just how strong a floor should be for safety, or how stiff for comfort. The generally accepted rule that the deflection under design load should not exceed $1 / 360 t h$ of the span was derived to prevent deflections which would cause plaster cracks.

I have yet to find anyone who can give what I would consider a satisfactory reason for the degree of deflection which should be permitted in residential floors when plaster is not used, or any valid reason as to whether this deflection should be for an evenly distributed load, a static, or dynamic concentrated load. Possibly a better approach would be to specify that the elastic limit should not be exceeded in the floor structure under conditions of maximum probable load. This might be functionally defined as the impact of two couples per square yard doing a "jitterbug" or some other violent form of dancing. How to translate the wear and tear of jive into foot pounds for stress analysis may not seem to be in the realm of serious applied design, but until we have definite scientific knowledge of the functional performance requirements we will not have a sound basis for building codes.

One of the most important qualities to be designed into a floor system is sound insulation against impact sounds. A concrete floor slab might be designed to withstand ten or even one hundred times the design load and yet be of such character that the sound of a woman's heels striking the floor would be transmitted to the 
room below in a very objectionable manner. This transmission of impact sound is quite different from the transmission of airborne sound. Although heel impact would be clearly heard in the room below, such a floor might easily prevent the transmission of airborne sound such as people speaking, or a radio, etc. Concrete, which has been the generally accepted floor material in multi-story buildings, is very poor insulation against impact sound. Just what the material of the future will be we do not know, but it may be lightweight fibrous concrete, calcium hydrosilicate, or a lightweight gypsum or vérmiculite. These materials are relatively weak structurally when compared with concrete, but would be amply strong if used in a structural laminate in which metal or some other skin takes up the compression and tension on the surface.

The roof will combine most of the requirements of a floor, with the addition of insulating and weather factors required for a curtain wall.

If satisfactory materials are developed for exterior walls, floors and roofs, the major problem is taken care of and it should be relatively simple to develop a lightweight panel for partition use. One serious problem is the provision of adequate sound insulation. Insulation against airborne sounds varies almost directly with weight if a homogeneous material is used. In other words, a homogeneous partition weighing one hundred pounds will give approximately ten times as much insulation against airborne sound as a ten-pound partition. However, if the partition is not composed of a homogeneous material but of a combination of different materials, or the surfaces are structurally independent or connected by elastic or spring connections of some character, the sound insulation will greatly exceed that of a solid partition of equal weight. Work being done on sound absorption and sound insulation in airplane cabins should point the way to a solution to the problem of control of airborne sound and vibration in building construction, without resorting to mass to obtain sound insulation.

\section{Appearance}

The question is often raised as to whether people will accept these radically new materials and construction methods. They will if the materials and methods are a real advance over present materials from the standpoint of economy and quality, provided the producer or designer gives them a satisfactory surface color and texture. One might raise the question as to whether the public would accept lead paint as a finish for walls. The answer here would be determined to a considerable extent by the pigment used and the personal taste of the potential client. Some prospects might accept lead with almost any pigment, other tenants would refuse to live in a room, the surface of which was covered with lead paint, unless the pigment used appealed to their taste, be it good or be it bad. The same principle will apply to surface color and texture of radically new materials. They will not be offered to the general public by the speculative or operative builder unless there is an economic advantage to himself. They will be accepted by the buying or renting public if they 
"like the looks"-in other words if the color and texture appeal to the individual prospect.

Although color and texture is all important in determining acceptability of a material, shape and window arrangement are of major importance in determining public acceptance of a dwelling unit. I should like to point out in this connection that the great majority of people have many more preconceived ideas as to shape of a single-family dwelling than they have in relation to an apartment house. It will be easier to put over on a mass scale radically new forms of multi-story buildings of various types than it will be in single-family houses where familiar forms play such an important part.

We have an interesting commentary on the acceptability of a new material in the case of office furniture. Originally filing cabinets were of wood in which the natural grain showed through a coat of varnish. With the advent of the metal filing cabinet the metal was finished to imitate wood. Later on the public accepted the idea of finishing the metal a dark green color which in no way imitated wood. Due to the shortage of metal during the war, it was necessary to manufacture wood filing cabinets and these were made in design and color to look as though built of metal. I think we may find the same thing happen in the field of building materials: first, new materials finished to imitate existing materials, then a finish suitable for the material and its function, and finally traditional materials developed in imitation of the new materials. In fact architects sometimes develop designs in advance of the materials which are available. For example, in Paris in 1933 when I was looking at a community of homes in the modern style, the architect who was showing them to me said, "To properly understand modern architecture it is well to remember that it is as if the modern architect said 'some day we will have new materials. When we have new materials we will have a new construction method. When we have new materials and new construction methods we will have new architecture. We have not the new materials, nor construction method, but we will have the new architecture anyway." "

Many of the so-called modern buildings in both Europe and the United States are merely a stucco or metal face on a traditional wall. They are attempting the streamlined aesthetics of the aero-dynamic age with century-old materials. The fact that so many of our commercial buildings, particularly stores, have departed from the aesthetics of traditional materials, would seem to indicate that our so-called merchandising experts are not too afraid of public acceptance of new forms.

If the people of the United States, meaning government and/or private industry, spent $\mathrm{I} / \mathrm{r} 00$ as much time, effort or thought on housing research as they spent on research during the late war, the results would not only revolutionize the construction industry, but would be of estimable value to humanity and/or profit to the new housing industry. 